\title{
The Weakest Link — Ground Support Observations at Some Canadian Shield Hard Rock Mines
}

\author{
B.P. Simser Craig Mine, Xstrata Nickel Ltd, Canada
}

\begin{abstract}
The design of ground support systems is complicated by the fact that a weak link in the system can cause premature failure. Pull tests and/or dynamic test results may not be representative of how the tendon/plate/retainment system interacts with the rock mass. For example it is relatively common to see rockburst damage where the rock has shattered around the tendons, with only superficial damage to the tendons themselves. The ability of the retainment system to transfer load to the tendon elements may be critical to the ultimate success of the system, especially in bursting ground. Variable stiffness of different components can also lead to premature failure of one element prior to utilising the full capacity of another.
\end{abstract}

Underground observations for both static and dynamic loading are used to discuss potential improvements and limitations of commonly used support elements (friction bolts, resin rebar, mechanically anchored rockbolts, cablebolts, weld mesh screen, plates, shotcrete). The observations are predominantly from Xstrata's Craig Mine in Sudbury, Ontario, Canada, with some examples from other Xstrata Canadian operations. The minimum support standards at the various mines are more than adequate for most conditions. However the exceptions (where something fails) often provide more insight and the observations are focused on these cases.

The mining methods are a mix of post pillar cut and fill and blasthole open stoping, utilising trackless development where tunnel size is $5 \times 5 \mathrm{~m}$ or larger. For "static" or pseudo static loading many of the observations come from cut and fill mining where breasting through the previous cuts' back offers an opportunity to see a cross section of both the stress induced fracturing and the previous cuts' back support. The mines are all hard rock Canadian Shield operations where the horizontal stress is approximately double the vertical (vertical stress being predominantly due to the weight of overburden). Some rockburst damage is shown and a brief recap of some dynamic testing is given to illustrate that at least some of the support design issues can be simulated, even if the detailed response of a particular rockburst cannot be practically duplicated.

\section{Introduction}

Design of ground support systems is complicated by many factors including the varying stiffness of different components. The static and dynamic capacity is not simply the sum of the capacities of each individual component since a soft retaining element like screen will require high deformation prior to reaching capacity (in the order of 100's of mm), whereas stiff elements like rebar could snap if localised deformation occurs over a small portion of the bar (in the order of 20 to $30 \mathrm{~mm}$ ). Another important consideration is the weakest link, where a portion of the system fails prior to the theoretical capacity of the component. For example rock falls can occur when weld mesh screen peels open between the overlap of two sheets, not necessarily breaking wire strands. Resin grouted rebar often has the plate torn over the nut allowing fractured rock around the opening to displace despite not breaking the rebar itself.

This paper is largely a collection of ground support observations from several of Xstrata's Canadian Shield hard rock mines. Most are from Xstrata's Craig Mine which is medium sized nickel/copper producer in the North range of the Sudbury basin. Mining is a mix of cut and fill and open stope blasthole. Depth ranges from about 1300 to $1700 \mathrm{~m}$ below surface with the horizontal stress being approximately double the vertical. Rock units vary from good quality blocky ground to very good quality granitic material with occasional poor quality dykes. Faulting is generally related to the most difficult ground conditions and has been known to generate rockbursting. Mechanically anchored rockbolts, resin grouted rebar, friction bolts (inflatable style and splitset style), cablebolts, retaining elements (screen, straps, plates), and shotcrete are discussed. The 
emphasis is on relatively common Canadian hard rock mining practice, which is often dictated by the type of mechanised equipment used to install the support.

\section{Weakest links}

For bursting ground in particular it is common to see ground failures with the tendon support (various types of rockbolts) virtually intact. The rock peels out around the bolt (Simser et al., 2006), often only deforming the collar area of the support or tearing the plate off but not breaking the bar itself. Observations from South African Gold Mine rockburst studies showed that about 70\% of the rock ejections were mainly due to failure of fabric support with the majority of the tendons still intact (Guler et al., 2001). The following section is largely a collection of simple underground observations which demonstrate the need for some conservatism with respect to support design (given the potential capacity may not ever get utilised).

\subsection{Bolt/plate connections}

One of the more common resin rebar failure modes in hard brittle ground is the plate ripping over the bolt nut or the nut breaking at the bolt threads. For $22 \mathrm{~mm}$ diameter rebar with hexagonal nuts (reverse spin - see Figure 1), a characteristic scar is often seen in the plates after blasting or strain bursting blows the plate over the nut. For example at Craig Mine 5 x 5 inch $(125$ x $125 \mathrm{~mm})$ flat steel plates have been used. They were switched from $1 / 4$ inch thick to $3 / 8$ inch thick $(6.35 \mathrm{~mm}$ to $9.53 \mathrm{~mm}$ ) to reduce the nut punching problem. Fewer incidences have been observed since this change but it generally is still easier to have the plate pop off than to break the rebar (for near surface deformations). The mine is also planning to increase the plate size to $150 \times 150 \mathrm{~mm}$, which is the practical maximum for the mechanised bolting machine being used.

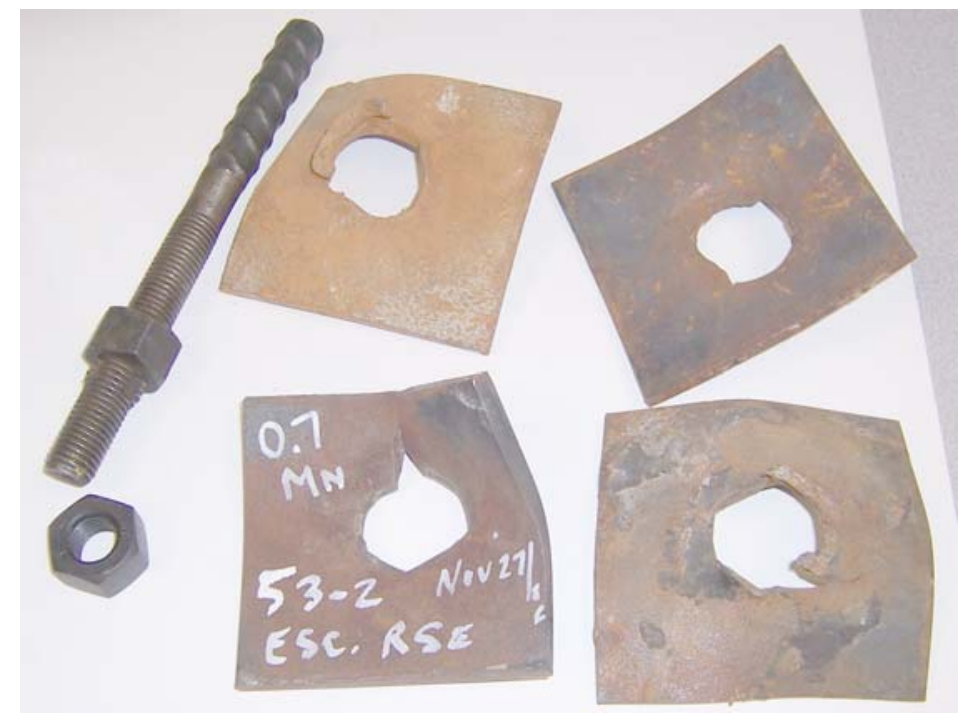

Figure $1125 \mathrm{~mm}^{2}$ rebar plates after dynamic loading. Left is end of $22 \mathrm{~mm}$ diameter rebar with hexagonal nut. Top left plate is $3 / 8$ " $(9.53 \mathrm{~mm})$ blown off rebar by wall slash (development blast), bottom left 3/8" plate blow off after Mn 0.7 seismic event locating $\sim 14 \mathrm{~m}$ away, top and bottom right $1 / 4 "(6.35 \mathrm{~mm})$ plates blown off after strain bursting. Note $\mathrm{Mn}=$ Nuttli Magnitude (Kaiser et al., 1996)

Similar observations have been made with other bolt types/plate combinations and also under "static" loading conditions. Where dome nuts are used on smaller diameter $20 \mathrm{~mm}$ rebar, they sometimes pop off and break the bar at the threads rather than the having the plate punch through the nut (Figure 2, right side). 


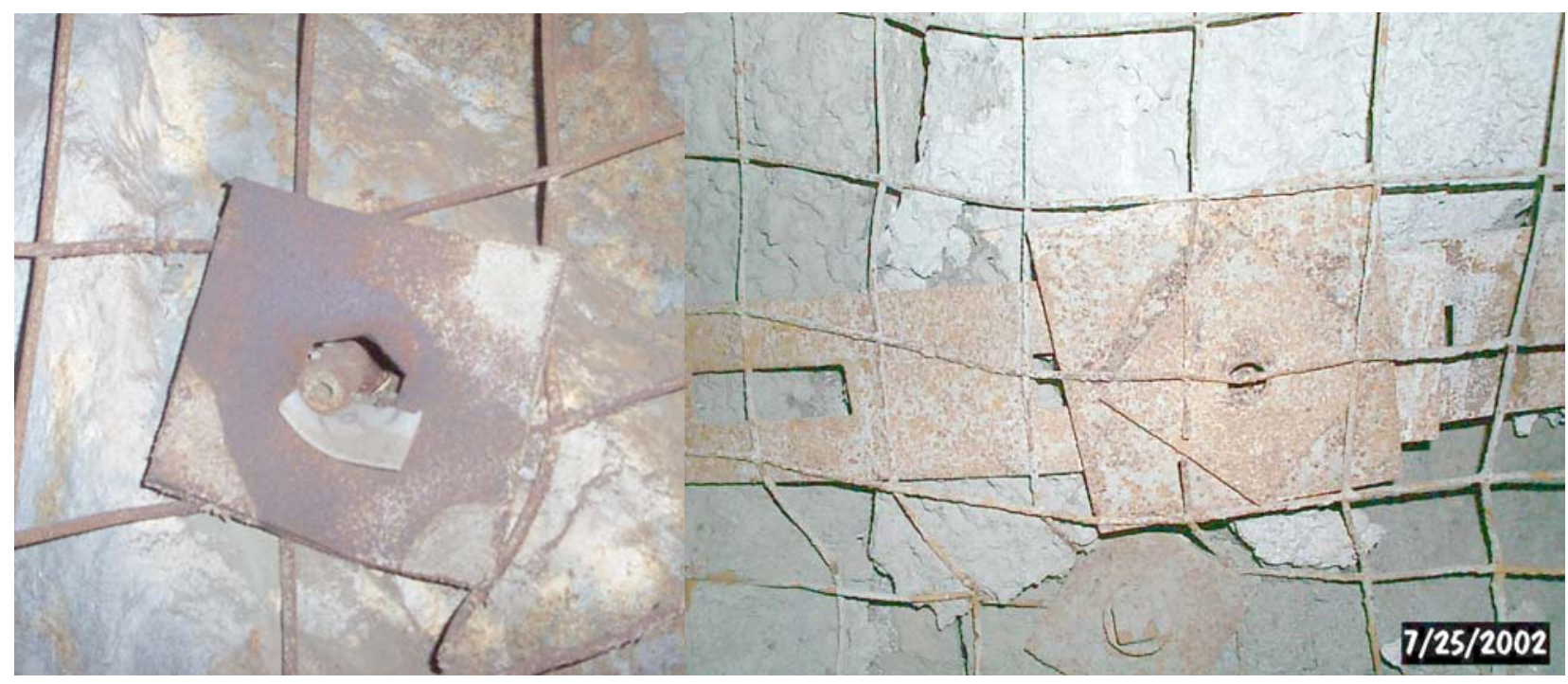

Figure 2 Left - $22 \mathrm{~mm}$ rebar in schist - bulking caused by schistose layers delaminating under load. Right $-20 \mathrm{~mm}$ rebar in meta-sediments, layered ground delaminates under high load causing heavy bulking. In this case the ground support included shotcrete covered by steel strapping and twin plates (7" 7 7" with 5" x 5" plate over top). The $20 \mathrm{~mm}$ rebar was installed with a dome nut which popped off (rockbolt seen below rebar plates, $100 \mathrm{~mm}$ aperture weld mesh in both photos)

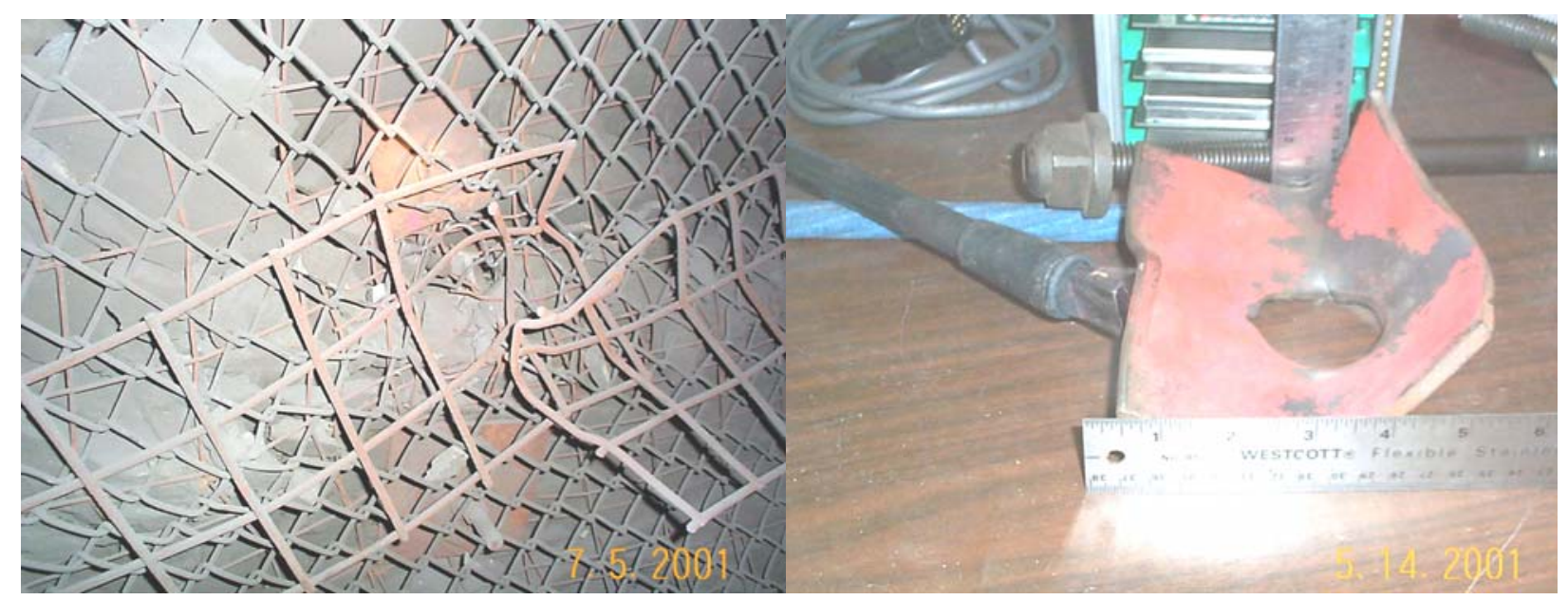

Figure 3 Modified conebolt plate failure. The $1 / 4$ " thick plate shown in the right photo was found $6 \mathrm{~m}$ horizontally from the photo on the left against the opposite wall of a drawpoint. It is quite possible that the bar had seen substantial shearing and the cone wasn't able to plough. Both the cone and mixing paddle as well as the domenut are shown in the right hand photo (similar type of dome nut as $\mathbf{2 0} \mathbf{~ m m}$ rebar example above)

Figure 3 also shows some broken mesh strap strands ( $7.7 \mathrm{~mm}$ diameter 00 gauge mesh) which the sharp edge of the plate helped guillotine (Figure 4 below also shows example of mesh getting cut by plates). It should be possible to make bevelled edged plates (Ortlepp, 2002) to reduce this effect, although the complications of manufacturing would likely increase the cost. Some mining camps use double plates, where a relatively thin large area plate is covered by the 'conventional' style plates shown above. Rubber backed plates (Li, 2001) or timber backed plates have been used to both dampen peak loads and reduce the cutting into the mesh. Generally speaking, the addition of the mesh strapping (Simser et al., 2006) has greatly improved the support by increasing load transfer to the tendon and it is rare to see the strap strands broken. 


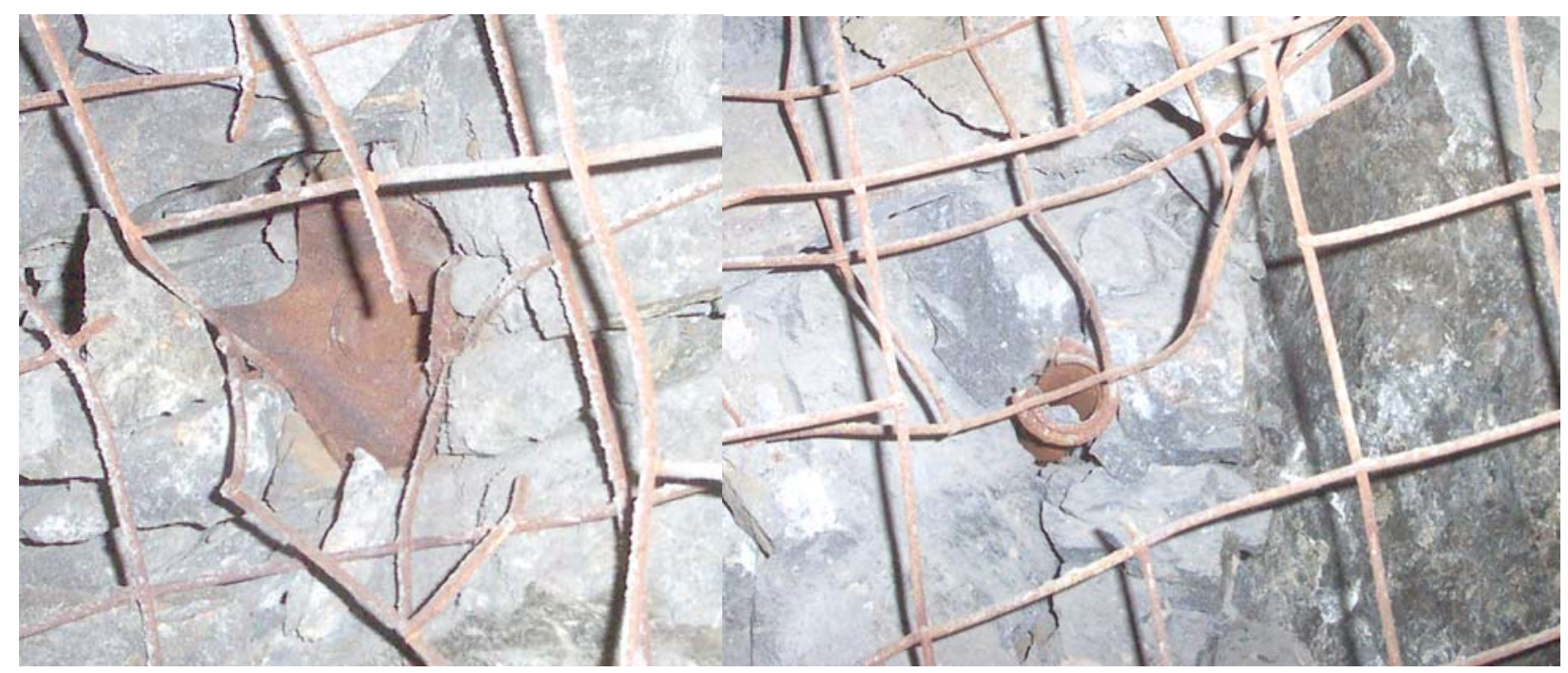

Figure 4 Left $-35 \mathrm{~mm}$ friction set (splitset style bolt) with folded plate and broken No. 7 gauge mesh strands (wire strand capacity about $0.9 \mathrm{t}, 4.5 \mathrm{~mm}$ diameter). Right - same wall - friction set with plate torn off. Mesh strands also broken. A slip plane can be seen in right half of photo. This chloritised structure caused localised movement on the wall, pinching the bolts not allowing them to yield. Mesh is $100 \mathrm{~m}$ aperture for scale. Bolt length is $\mathbf{1 . 8}$

The use of yielding tendons can reduce the premature plate failure problem. In Figure 4 the splitsets likely could not yield due to shearing along the structure offsetting the bolts. Similar problems are common in laminated ground and at La Ronde Mine (Mercier-Langevin and Turcotte, 2007) they have introduced rebar inside the splitsets to enhance both the pull out resistance and the shear strength. This method also increases corrosion resistance of the splitsets and the rebar nut/plate over the splitset plate reduces the impact of this weak link.
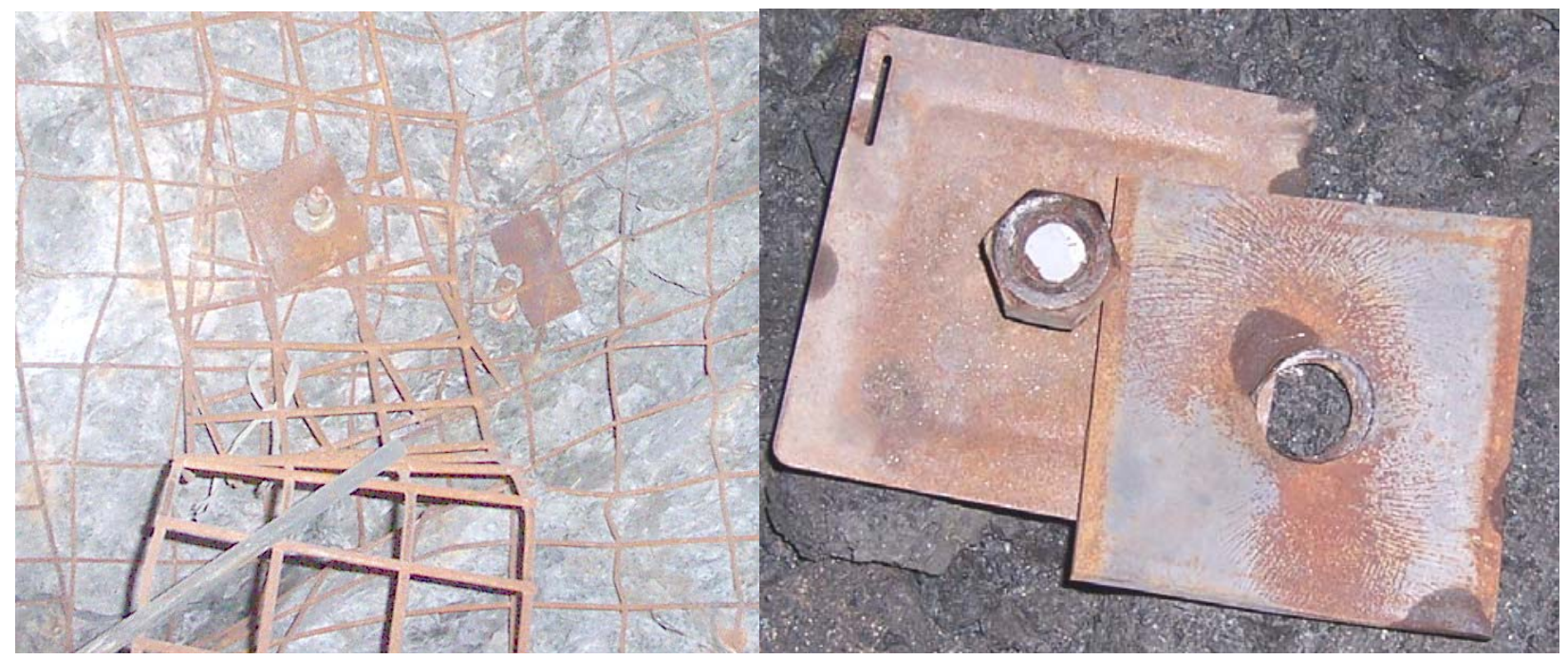

Figure 5 Left - rebar plate ripped in half immediately to the right of conebolt (yielding tendon) over 00 gauge strap. This area experienced dynamic loading from a Mn 2.6 event approximately $15 \mathrm{~m}$ away. Right - No.7 rebar snapped at threads. A small amount of rust can be seen on the otherwise fresh bar break probably due to eccentric loading/bending of the bar (push plate seen on bottom, rebar plate on top)

In Figure 5 above (left side) modified conebolt plates over top of heavy mesh straps survived a relatively large magnitude event, but the stiff rebar (without the loading spreading strap) had its' plate ripped in half. The right side of Figure 5 shows a close-up of a $22 \mathrm{~mm}$ rebar broken at the threads. In this case careful 
examination of the bar shows a bit of rust on the otherwise fresh break. With the pre-existing crack in the bar it was easier to break at the threads rather than punch through the plate.

Getting the exact plate strength to match the bar strength may not be practically achievable because of irregular rock surfaces and un-even plate loading. The 3/8” plate punching resistance appears to be relatively close to the $22 \mathrm{~mm}$ rebar strength but still tends to bend prior to failure allowing a simple visual (qualitative observation) for bolt loading. The $1 / 4$ ” plate also allows a good visual sign of bolt loading but arguably punches through too easily.

\subsection{Mesh and mesh/bolt connections}

Push plating (Figure 5 right, Figure 6 arrow) is often used to attach the next development advance mesh to the previous advance. The plates are designed to go over the rebar threads with a pull off strength a bit stronger than the mesh strength. They are placed over the main rebar plate so aren't that well coupled to the rock surface and don't often pull off under load. The mesh bagging is rarely sufficient to pull off the push plate as it would break the wire strands first and for strain bursting, the rebar plate gets hit first.

The use of weld mesh sheets (screen) is popular in typical Canadian Hard Rock Mines. Different wire thicknesses are available, with most operations balancing ergonomics (weight of a sheet with respect to manual handling), cost and performance. In some operations \#9 gauge has been found to be "light" and prone to blast damage and premature failures, and switching to \#6 gauge led to less re-work. Xstrata Sudbury operations generally use \#7 gauge. Better performance comes from heavier mesh, however peeling apart along the screen sheet edges is often the problem rather than the wire strength. Even with 2 to 3 square overlaps (200 to $300 \mathrm{~mm}$ ) the seam can split open more easily than breaking a line of wire strands (Figure 6).

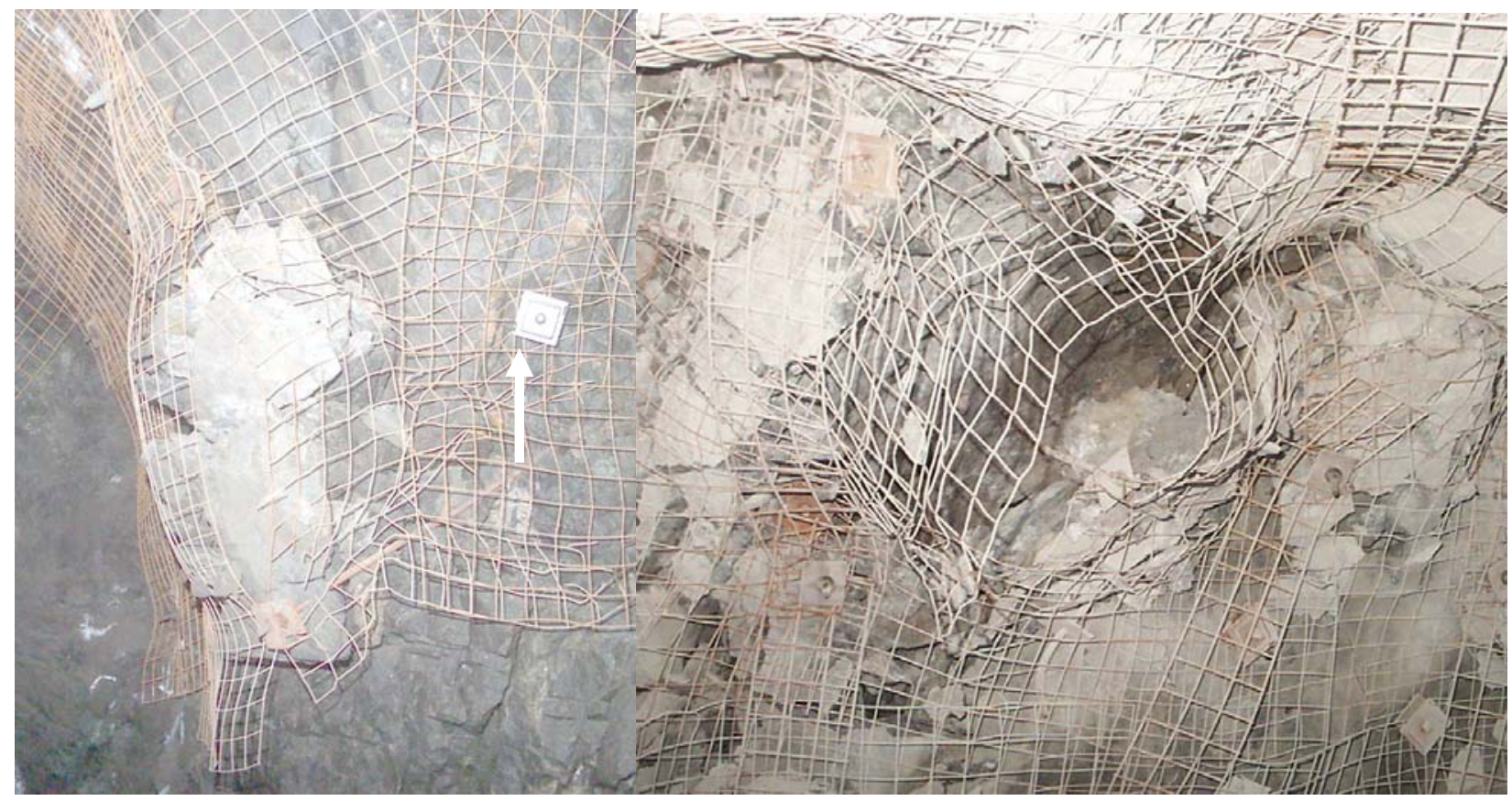

Figure 6 Left - bulking in blocky ground. Wall screen is splitting at seams; a push plate is denoted by the arrow. Right - back screen between straps and conebolts after Mn 2.0 event approximately $10 \mathrm{~m}$ away (about 1.5 tonnes of loose spilled out) 


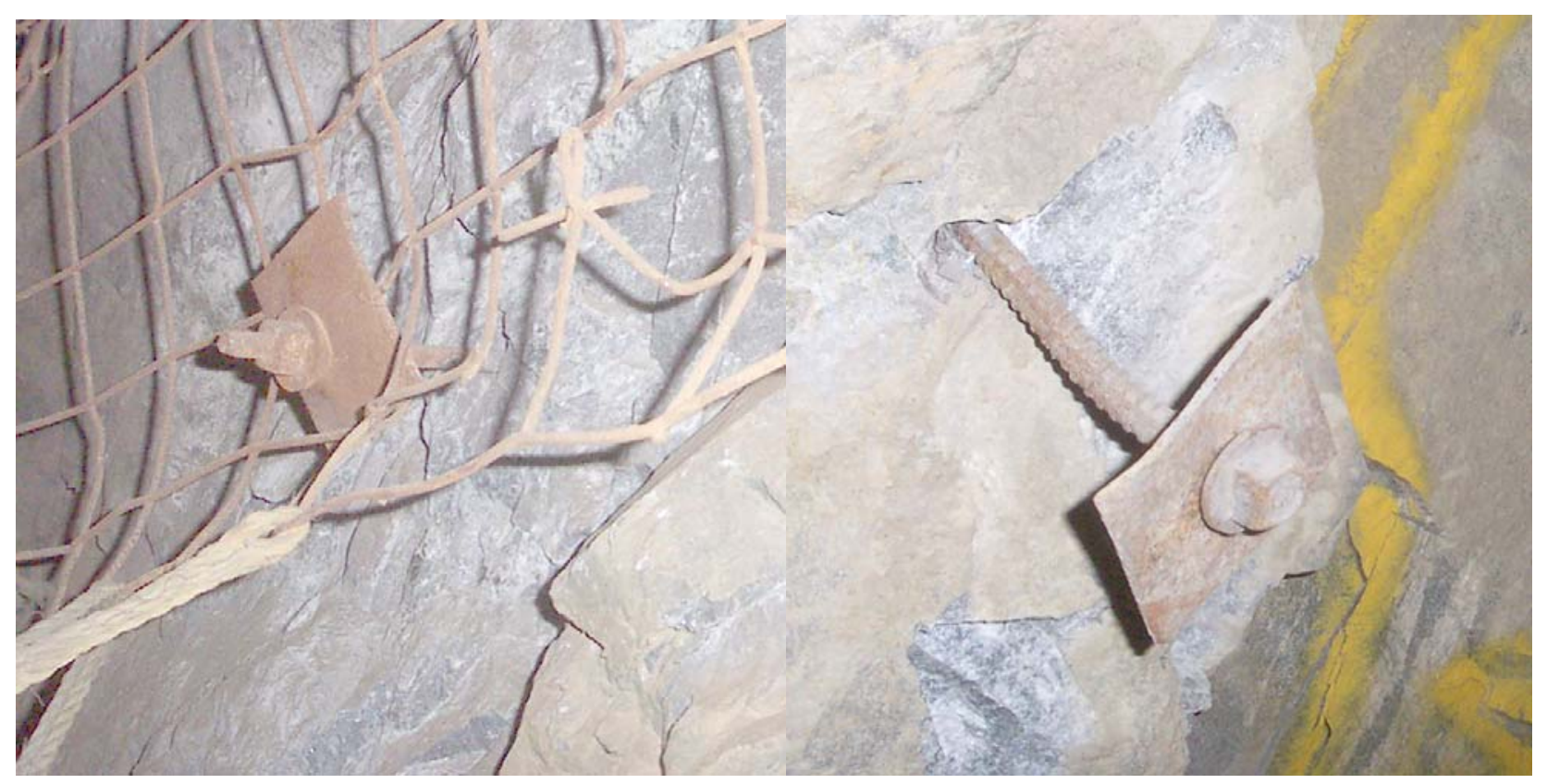

Figure 7 Left - Zero capacity bolt - mechanically anchor rockbolt in wall - plate is vertically aligned allowing minor spalling to fall out more easily due to gravity - once the plate has lost contact, the end anchored bolt is no longer supporting anything. Note also lowest wall screen can allow small material to spill out (open ended between bolts). Right - forged head rebar - spalling caused plate to lose contact (similar to left photo) but at least there is a fully bonded ripple bar in the hole still acting as ground support. The forged head arguably avoids the inherent weakness conventional rolled or cut threads cause (although forging changes steel strength) but the plate can only be held tight to the rock during installation, not tightened up later as threaded bar allows

Plate size is sometimes dictated by equipment, especially with some mechanised bolters using a carousel configuration that won't fit large plates. Thicker plates (e.g. 3/8” versus 1/4") do not pull off as easily but don't give as clear a visual sign of ground support taking load (less bending). Good coupling to the rock can also be an important factor, although threading the bar can introduce a weakness, it does allow an inexpensive way to get the plate tight to the rock. Some friction style bolts (e.g. swellex) have to rely on a bit of bolt "shrinking" as it is expanded to get the plate tight. The lack of tight coupling with the rock may actually avoid the potential weak link of the welded bushing or a plate ripping over the bushing. Externally threaded bar (e.g. dywidag) offers an obvious improvement, again usually at higher cost.

Figure 8 shows a rockburst in the back of a blasthole overcut that likely occurred with the blast. It became accessible after filling the panel several weeks later. The failure occurred after the last line of modified conebolts and straps where only rebar/screen and cables were installed. Experience has been that the load spreading straps help prevent the rock from shattering out around the bars, which is as important as the use of yielding tendons (modified conebolts installed through the straps in this case) for rockbursting conditions. The bottom right photo shows two intact rebar, one intact cable, and two screen seams. Although some rebar and screen failed (e.g. bottom left photo), most of the fallout was allowed by retainment loss (screen peeling open at seams, rock shattering out around tendons). 


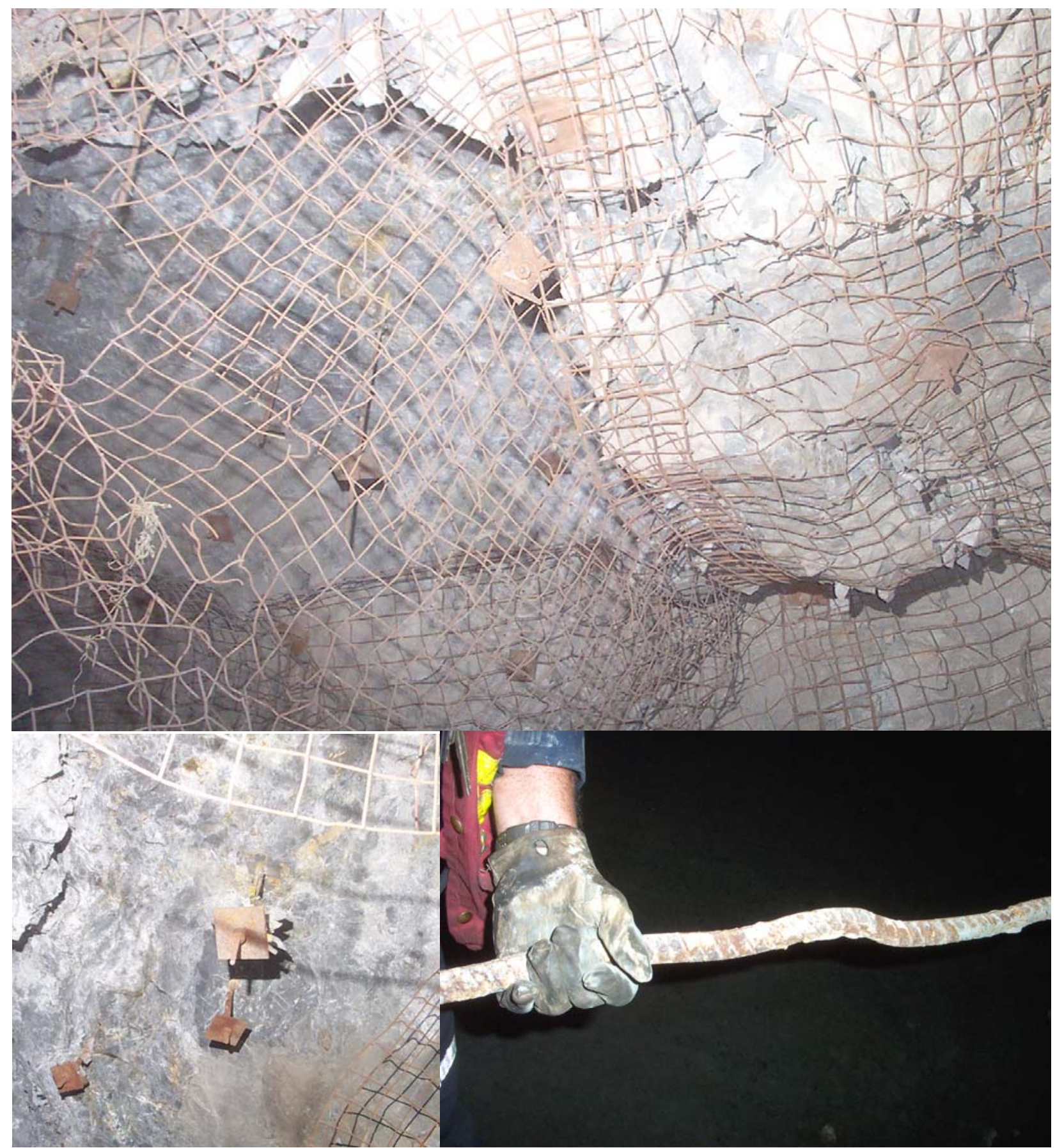

Figure 8 Back burst in blasthole overcut after floor mined out

\subsection{Corrosion}

Thin walled friction bolts and mechanically anchored rockbolts are well known to be prone to corrosion problems. In theory a mechanically anchored rockbolt could perform quite well, being able to accommodate movement between the shell and the plate. In practice slip or failure of the mechanical shell often occurs prior to breaking the bar, and the entire assembly is prone to corrosion. It is not always possible to detect severe corrosion problems by visual assessment alone, examples of rockbolts and friction style bolts corroding in the hole with an apparently "good" protruding portion occur as per Figure 9 below. 


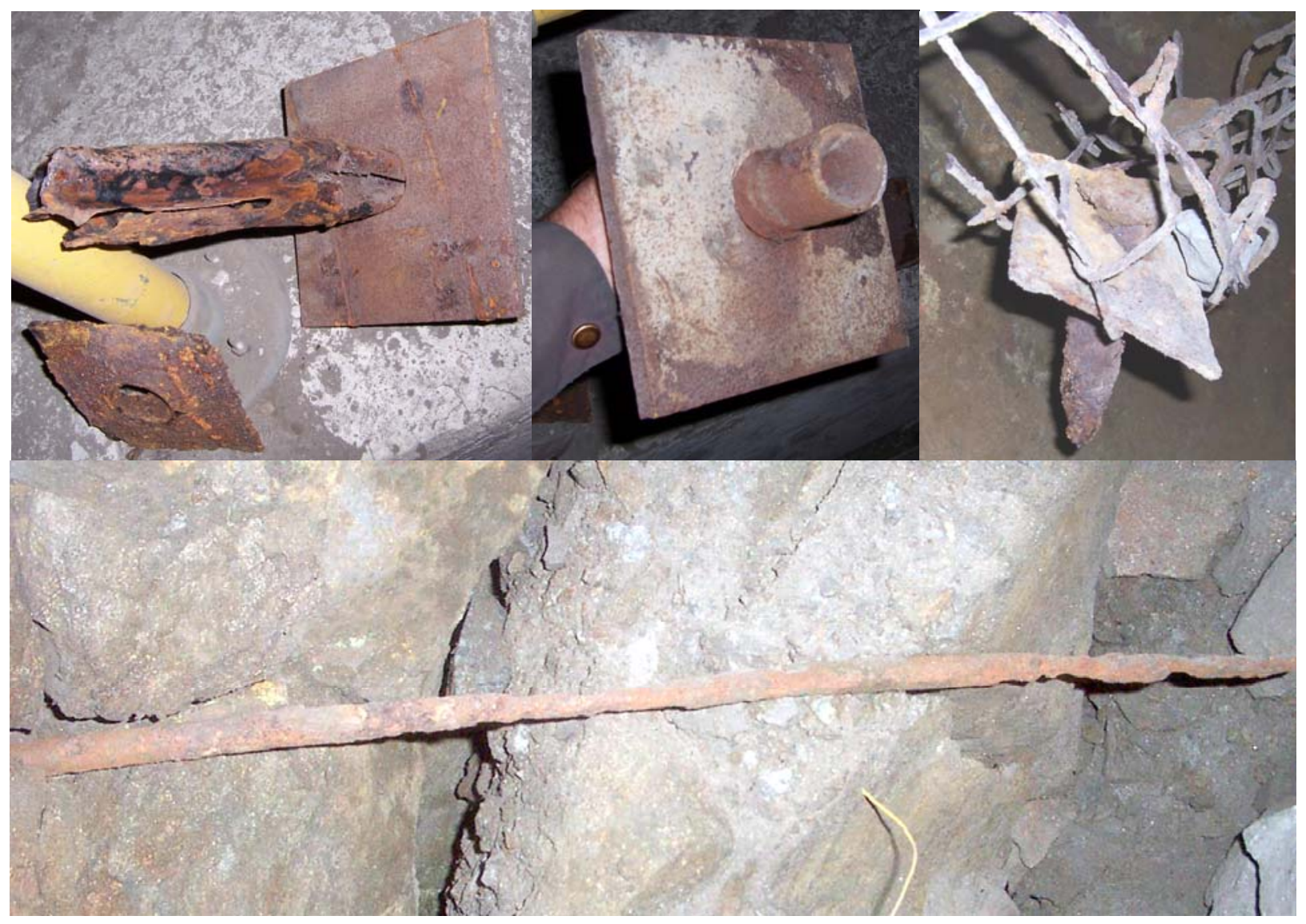

Figure 9 Upper Left - Super swellex bolt approximately 6 months old after being exposed by a small fall of ground. It was installed in a wet area in massive sulphide material (corrosive). Centre - same swellex bolt viewed from plate side with apparently only moderate corrosion. Upper right - friction set (split set) after approximately 2 years in an area with limited ventilation (high humidity). Bottom - mechanically anchored rockbolt with variable corrosion along its length (installed in massive sulphide material $>5$ years, was exposed during rehab)

\section{Rebar}

There are various pros and cons with different support systems, in Figure 10 a super swellex bolt and a $22 \mathrm{~mm}$ rebar were both exposed in the lower wall of a cut and fill stope (breasting through the previous cuts' back support). The relatively thin wall swellex is prone to both corrosion and tearing when sheared, whereas the resin encapsulated rebar can bend significantly (see Figure 8 for example) and is generally resistant to corrosion. The swellex however was intended for the relatively short duration of a cut and fill lift and is generally simpler to install with fewer potential quality problems. Resin cartridges can have issues with obstructions in the hole, over spinning, shelf life, catalyst evaporating, etc. At Craig Mine the super swellex are used in $3.5 \mathrm{~m}$ or connectable $2.4 \mathrm{~m}$ lengths as "long” support generally for wider spans and/or structural wedges in cut and fill mining. For more permanent development or longer duration mining sequences (some blasthole accesses) cables are preferred because they can bend in shear and the grout protects them for rust. Rebar are used most of the time for standard support because of their ability to 'knit' together stress fractured rock and control rock bulking (Kaiser et al., 1996). In heavily fractured ground (example developing through failed and dilated rock) it is sometimes necessary to use splitsets and/or swellex to ensure higher quality installation because of difficulty keeping resin cartridge plastic sleeves from shredding prior to filling the hole. 


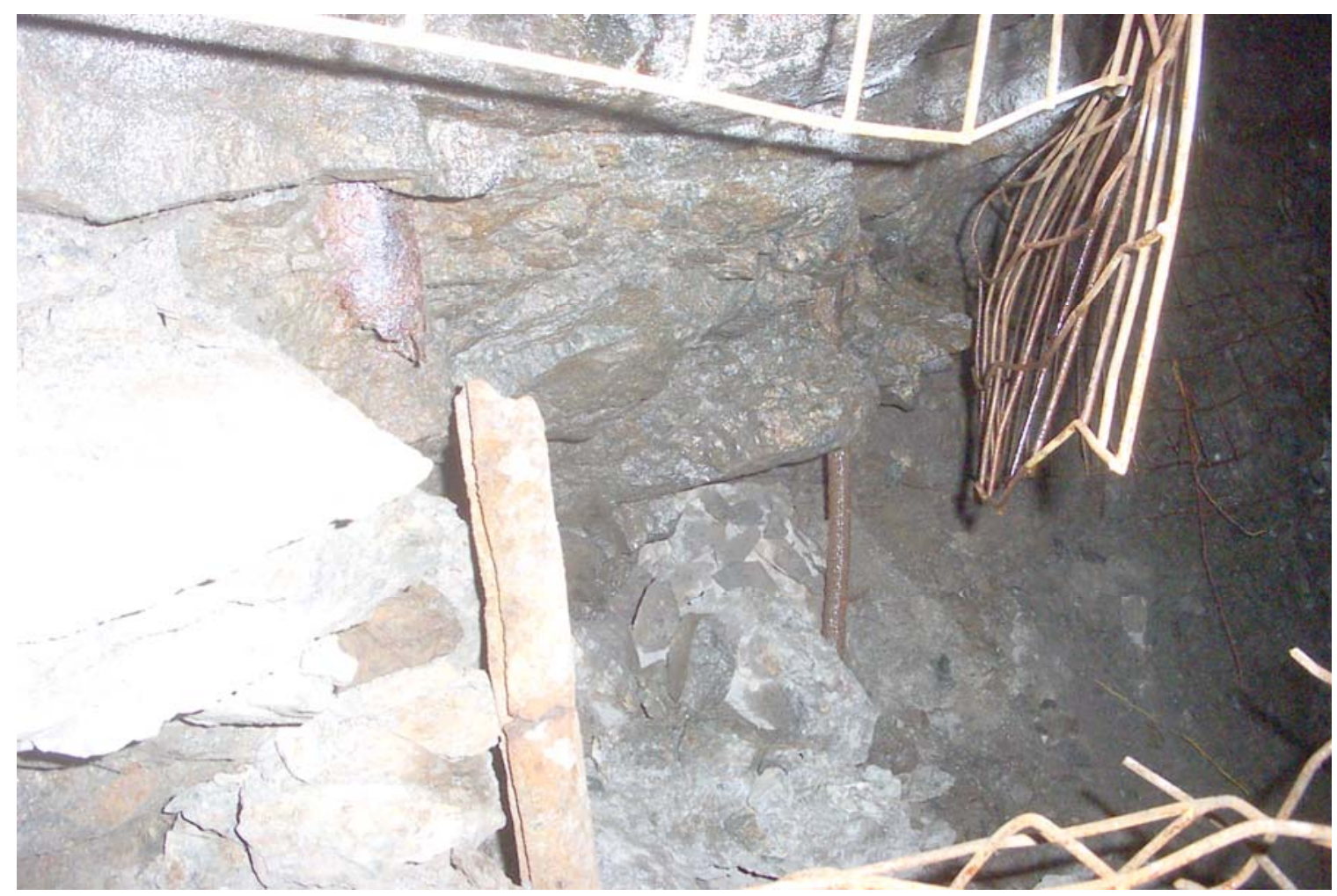

Figure 10 Sheared super swellex exposed in cut and fill mining. The rebar in the background was bent but not broken

The heavily sheared rebar shown in Figure 8 illustrates several points. Although the end was sheared off (not in photo) the bar deformed at several locations along its axis resulting in substantially more deformation capacity than a simple pull test would imply. For example a typical rebar pull test might have failure displacement in the order of 20 to $30 \mathrm{~mm}$. If the bar displaces along multiple portions (for example in stress fractured ground with multiple fractures dilating) it may be able to deform to much greater total amounts.

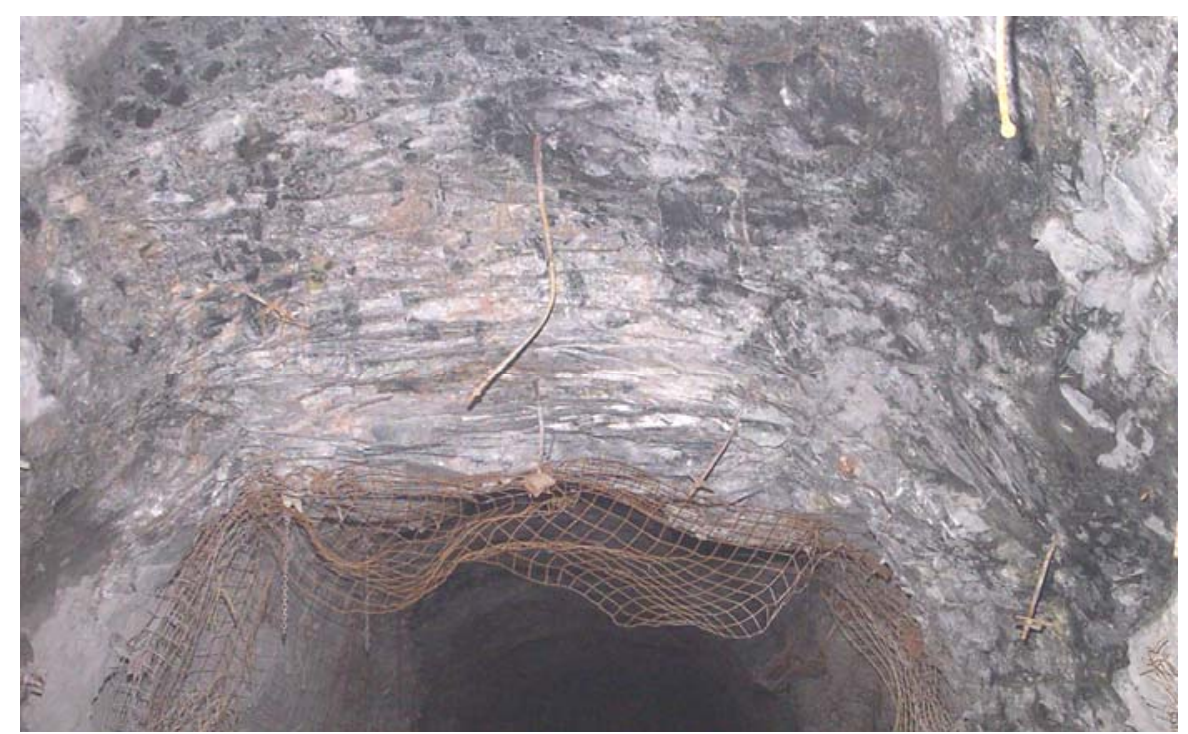

Figure 11 Stress fracture 'arch' exposed in cut and fill access. Accessing the subsequent cut is done by "taking down the back" of the previous cuts' access providing a sectional view through the fracture zone. $5 \times 5 \mathrm{~m}$ access 
It is reasonable to take some support credit for the arching or laminated beam effect of keeping the fracture zone together (reinforced rock arch - Lang and Bischoff, 1982). However driving an excavation off to the side at a later date can de-stabilise the arch and heavy scaling in the back and upper shoulder is often required.

\section{Shotcrete}

Shotcrete can have a positive role in most support systems by helping to reinforce inherent weaknesses in the rock mass and help the rock support itself by not allowing small scale key blocks to un-ravel. However it is relatively brittle and due to cost limitations normally applied in relatively thin skins (example in Figure 12 had prescribed thickness of $75 \mathrm{~mm}$, with actual thicknesses in the 50 to $100 \mathrm{~mm}$ range). In severe cases such as violent bursting or heavy squeezing ground it is often necessary to apply mesh and tendon support over the shotcrete.

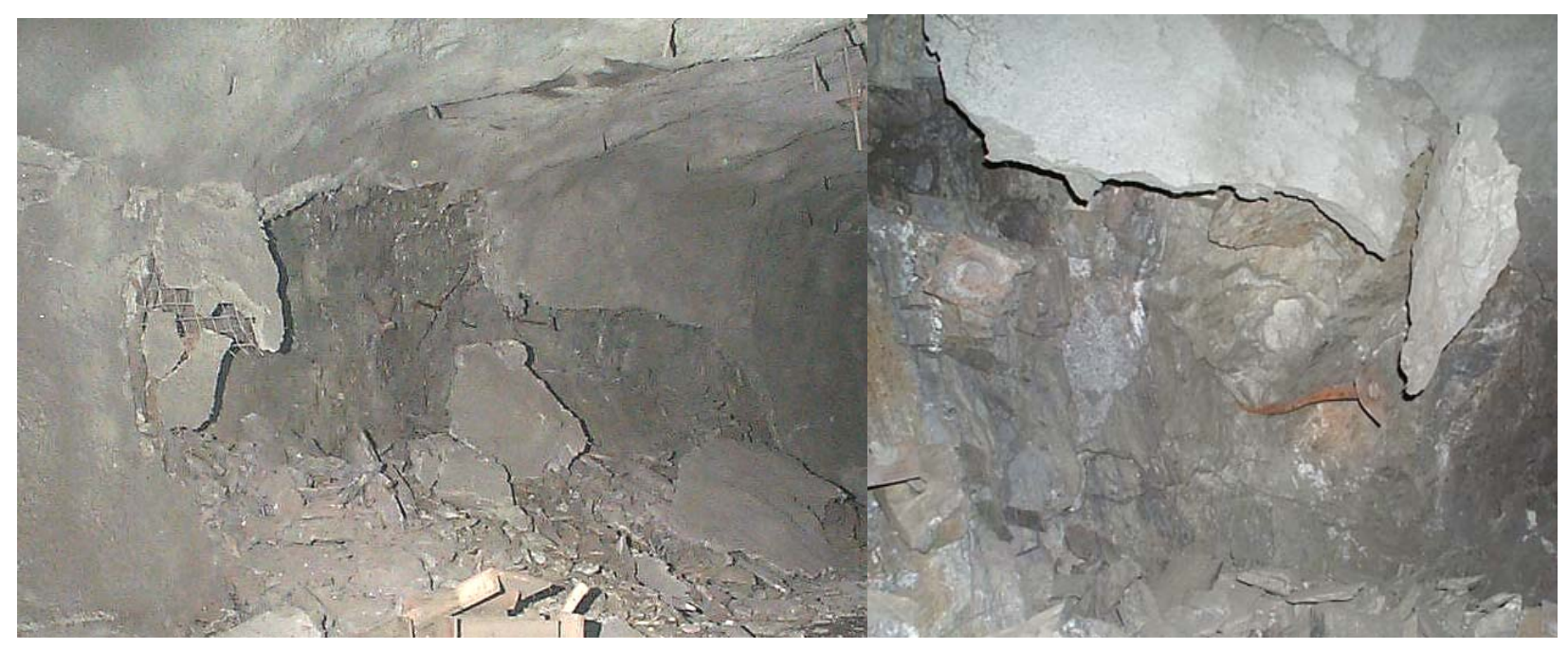

Figure 12 Shotcrete after rockbursts (two separate incidences). Both had dramix steel fibres in a prescribed thickness of $75 \mathrm{~mm}$. Left photo also had No.9 gauge weld mesh in top half of wall. In both cases about $75 \%$ of the bolts were left virtually intact (mix of splitsets and No.6 rebar). In both cases the shotcrete was applied over the primary support (rebar, splitsets and screen) and thus didn't help transfer load to the tendons

The requirement for shotcrete is usually a cost/benefit decision. A shaft only access and relatively spread-out mature mine may find the logistics prohibitive. For example Craig Mine normally uses dense bolting and durable mesh to control spalling ground, and selectively enhances it with shotcrete to prevent re-work caused by corrosion, machine damage, and blast damage (particularly truck loadout areas, sumps, and above slot raises). The mine often sprays the back where up-hole blastholes (uppers) are being drilled to prevent small scale un-ravelling of the fracture zone. Systematic shotcrete may be more applicable where productivity gains over mesh are realised and the life of mine excavation deformation does not exceed the liner capacity. It can also successfully control some strain bursting and blast vibrations (Kaiser et al., 1996) but as shown in Figure 12 above it can eject from the excavation surface during larger rockbursts.

\section{Dynamic support testing}

"From previous testing it had become apparent that, because of a strong tendency to cut individual wires of the mesh, the sharp cropped edges of commercially - available washer-plates represent a serious weakness in the connection between the containment and retainment elements of a support system. Washer-plates are often formed from sheet steel that is insufficiently thick to resist folding and tearing during a rockburst” (Ortlepp, 2002). 
Examples of the above quote can be seen in Figures 1 through 5. Dynamic testing of support systems (e.g. Villaescusa, 2007) has received considerable attention in the last decade or so and can help identify the weakest links. Although it is difficult to precisely simulate a rockburst with blasting or drop weight tests, the effects of dynamic loading can be at least qualified. Rockbursts vary greatly in their character, for example, a large fault slip burst might involve a low frequency seismic wave triggering a strain energy build-up of brittle rock around a tunnel. Blasting induced rockburst experiments may involve high frequency shock waves with substantial gas heave. Dropping a large weight on a support element, although simple and repeatable does not take into consideration seismic wave effects and it is difficult to duplicate the support system rock coupling. However given the potential severity of rockburst damage, and the abundance of different support elements available, there is still merit in further testing work whether or not it represents an exact underground burst.

\subsection{Crude NTC drop tests}

Prior to the closure of the Noranda Technology Centre (NTC) some preliminary drop tests were performed on $22 \mathrm{~mm}$ diameter rebar (Simser, 2003). Although the data is not comprehensive, it does demonstrate the need to understand weakest links and consider how the load will be transferred to the tendon. The NTC dynamic drop test rig (improved version now at CANMET - Plouffe, 2006) was used to scope the viability of using toe anchored rebar as a yielding support. This technique, which relies on the steel stretching to absorb energy has been successfully implemented (Turner and Green, 2005), with the cautionary note that permanent plastic elongation of steel is irreversible so the support may have to be upgraded after high deformations. The principal of debonded cables (Bawden and Jones, 2002) is another proven technique where the ductility of steel allows substantial plastic deformation to accommodate larger ground movements.

Three toe anchored rebar were tested by spinning them into a thick walled steel tube and subsequently dropping a $1023 \mathrm{~kg}$ weight onto the bolt plate (see table 1 and Figure 13 below).

Table 1 Summary of dynamic rebar tests at NTC test facility (Simser, 2003)

\begin{tabular}{|c|c|c|c|c|}
\hline $\begin{array}{l}22 \mathrm{~mm} \\
\text { rebar }\end{array}$ & $\begin{array}{c}\text { drop } \\
\text { height } \\
\text { (m) }\end{array}$ & $\begin{array}{c}\text { Input } \\
\text { energy } \\
(\mathbf{k J})\end{array}$ & $\begin{array}{c}\text { Impact } \\
\text { velocity } \\
(\mathrm{m} / \mathrm{s})\end{array}$ & Observations (note $1022.7 \mathrm{~kg}$ mass) \\
\hline Sample 1 & 1.253 & 12.57 & 4.96 & $\begin{array}{l}2 \text { plates } 150 \times 150 \times 6.4 \mathrm{~mm} \text { and } \\
125 \times 125 \times 4.8 \mathrm{~mm} \text { domed steel with } \\
28.6 \mathrm{~mm} \text { holes, both ripped over hex nut }\end{array}$ \\
\hline Sample 2 & 1.220 & 12.24 & 4.89 & $\begin{array}{l}200 \times 200 \times 9.5 \mathrm{~mm} \text { flat plate with } 25 \mathrm{~mm} \\
\text { hole, } 0.97 \mathrm{~m} \text { free bar (from plate to resin } \\
\text { column), bar held no failure }\end{array}$ \\
\hline Sample 2 & 1.276 & 12.8 & 5 & $\begin{array}{l}2^{\text {nd }} \text { drop on sample } 2 \text {, bar broke at threads } \\
\text { flush with plate, total strain } 5 \%\end{array}$ \\
\hline Sample 3 & 1.235 & 12.29 & 4.9 & $\begin{array}{l}200 \times 200 \times 9.5 \mathrm{~mm} \text { flat plate with } 25 \mathrm{~mm} \\
\text { hole, } 0.625 \mathrm{~m} \text { free bar, bar broke at threads, } \\
\text { total strain at failure } 5 \%\end{array}$ \\
\hline
\end{tabular}

Although the tests were only exploratory in nature they help illustrate some key points. The first drop simply ripped the plates over the rebar nut, in a very similar fashion to the underground observations noted in Figure 1. Increasing the plate thickness prevented this. The rebar steel is rated for about $13 \%$ elongation, however the bars failed at the threads after approximately 5\% elongation (calculated as permanent deformation/free length of bar). Strain localisation at the threads didn’t allow the full utilisation of the potential steel strength. Externally threaded bars can help eliminate this problem. 


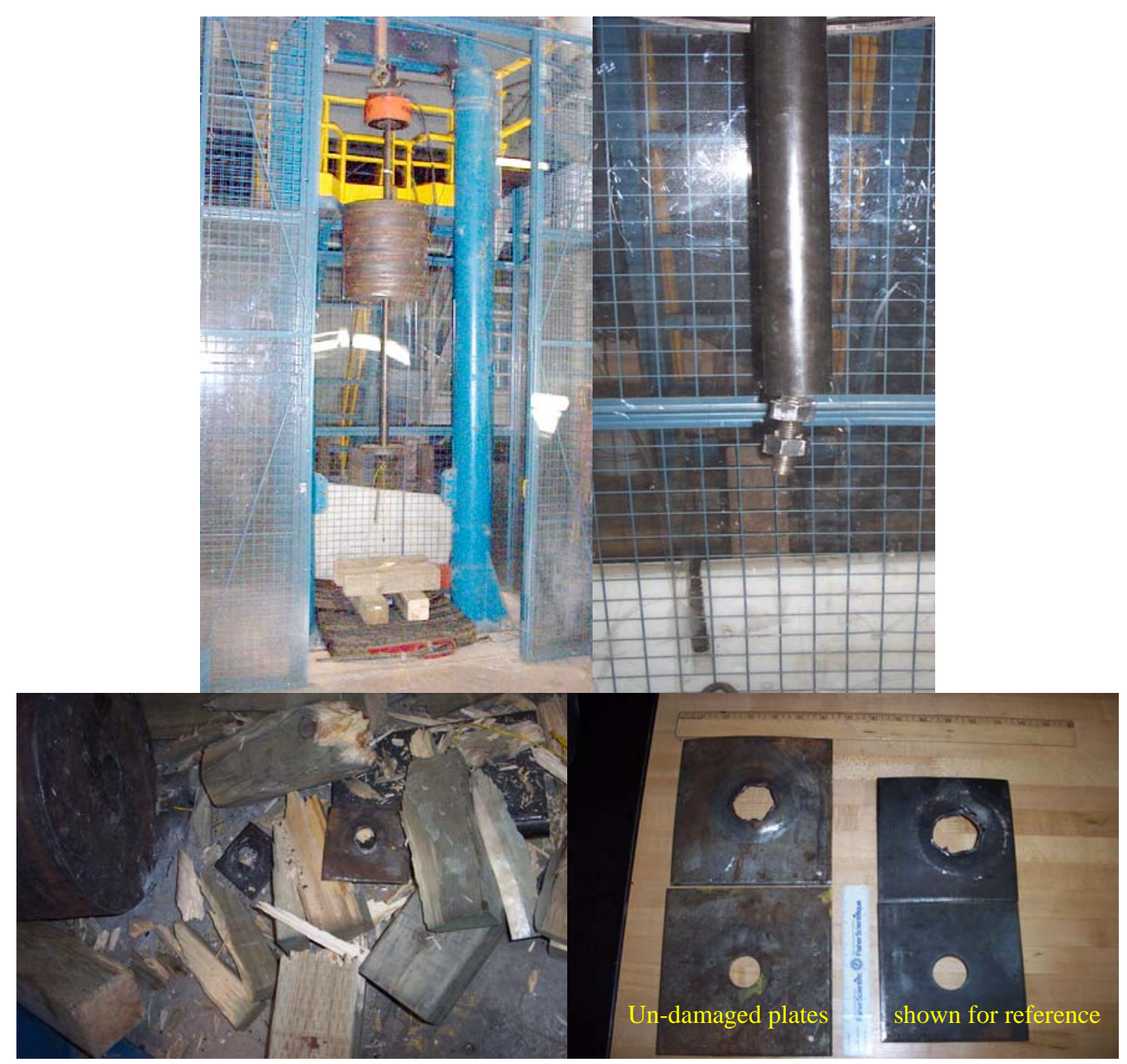

\section{Figure 13 Toe anchored rebar tests. Upper left test rig with mass in free fall. Right/below - results of first drop, plates tore over nut similar to underground observations in Figure 1}

Several drop weight panel testing programs have been performed in South Africa (e.g. Guler et al., 2001). One series of tests commissioned by NTC and conducted by Ortlepp (2002) compared conebolts with heavy mesh straps installed over weld mesh screen versus chainlink screen. The chainlink screen (50 mm aperture, no welds) should be able to absorb significantly more energy than weld mesh screen (100 $\mathrm{mm}$ aperture) because of the increased steel (smaller aperture) and flexible links. However by measuring load transfer to the conebolts it was demonstrated that the stiffer weld mesh panel generated $28 \%$ more yield in the conebolts than the chainlink panel. The trade off in this case becomes one of more flexible mesh with fewer overlaps (chainlink usually comes in rolls rather than sheets) versus easier to handle weld mesh sheets with better load transfer to the tendons.

Selection amongst available support systems often comes down to a balance of costs versus benefits. For example South African style meshing and lacing is often installed with rebar (end looped over to thread the lacing through). Intuitively stiff rebar might not perform well during a rockburst but the retainment system of chainlink and cable lacing is very soft and arguably doesn't transfer load efficiently to the bolts. The emphasis is to use the retainment system to contain the burst. Falconbridge (now Xstrata) also used this style support successfully (Davidge et al., 1990) but Canadian labour costs made the routine application of this support system prohibitive. The use of modified conebolts over heavy mesh straps places greater emphasis on transferring the load to the yielding tendon. In the Canadian context strapping is easier to mechanise than 
lacing and therefore more economical to install. Dynamic support testing can compare different approaches without having to wait for a rockburst underground to get results.

\section{Conclusions}

There are a large number of different rockbolts and retaining elements available in the worldwide mining market. The above case studies demonstrated the performance of a few ground support systems that are commonly used in Canadian hard rock mines. A weak link in the system can often cause premature failure of a support system, never allowing it to reach its' theoretical design capacity. A common weak link is the bolt/plate connection. Several improvements have been used or suggested elsewhere, for example: rubber backed steel plates; bevelled plate edges; timber backed steel plates (similar to rubber backed plates where timber softens the blow); and plates over heavy gauge mesh straps.

One approach is to use a hybrid support system in burst prone areas. Stiff rebar limits rock mass bulking and is thought to create rock "beams" or "arches" around the opening. However dynamic loading can snap a stiff element, especially if the strain is localised, and the system can be supplemented by adding yielding elements in high risk areas. Modified conebolts and/or debonded cables with heavy weld mesh straps can perform this function. The ultimate yielding tendon will still not be effective if the brittle rock simply blows out around the bolt or rips off a weak link. Enlarged plates, strapping, and bolting through shotcrete all can reduce the likelihood of the rock from unravelling out around the bolts.

Shotcrete can enhance most ground support schemes but is not necessarily effective if it's on the outer layer of the support system in bursting ground. The inherent brittle nature of the material may necessitate bolting and meshing overtop (e.g. Lucky Friday Mine - Blake 2006). This also improves load transfer to the tendons. Otherwise, shotcrete can just become part of the "fly rock" or spall off the rock surface.

Laboratory testing may never duplicate the intricacies of an actual rockburst but can provide repeatable and reliable insight into how support systems behave under dynamic loads. It is important to consider load transfer to tendons and potential weak links in a support system. Continued industry support for testing programs such as WASM (Villaescusa, 2007), CANMET (Plouffe, 2006) and ACG (Heal et al., 2005) is endorsed by the author. Empirical underground experience will always be important but a proactive approach to solving deficiencies is a better path forward.

\section{Acknowledgements}

Permission to publish this paper from Xstrata's Sudbury Division is gratefully acknowledged. Thanks to my co-workers (past and present), particularly Rick Deredin whose 'hands-on' knowledge is an enormous asset to the Craig Ground Control Program.

\section{References}

Bawden, W. and Jones, S. (2002) Ground support design and performance under strong rockburst conditions. NARMSTAC 2002. Mining and Tunnelling Innovation and Opportunity, University of Toronto, pp. 923-931.

Blake, W. (2006) Review of Mining in High Stress Zones at Craig and Onaping Mines. Consulting report for Xstrata’s Craig and Onaping Mines.

Davidge, G.R., Martin, T.A. and Steed, C.M. (1990) Lacing support trial at Strathcona Mine. Proceedings $2^{\text {nd }}$ International Symposium on Rockbursts and Seismicity in Mines, Minneapolis, June 1988. Balkema.

Guler, G., Kuijpers, J., Wojno, L., Milev, A. and Haile, A. (2001) Determine the effect of repeated dynamic loading on the performance of tunnel support systems. Final Report - Safety in Mines Research Advisory Committee, South Africa. Project No. GAP 616.

Heal, D., Hudyma, M., Langille, C., Potvin, Y., Butcher, R., Ball, R. and Hartmann, B. (2005) In situ testing of ground support performance under strong dynamic loading. RASIM6, Controlling Seismic Risk. $6^{\text {th }}$ International Symposium on Rockburst and Seismicity in Mines, 9-11 March 2005, Perth, Australia.

Kaiser, P., McCreath, D. and Tannant, D. (1996) Canadian Rockburst Support Handbook. Geomechanics Research Centre, Laurentian University.

Lang, T. and Bischoff, J. (1982) Stabilization of Rock Excavations Using rock Reinforcement. 23 ${ }^{\text {rd }}$ USRM Symposium, pp. 935-944.

Li, T. (2001) Use of DE plates as replacement of dragonfly plates. WMC internal report for Junction Mine (kindly provided via personnel communication). 
Mercier-Langevin, F. and Turcotte, P. (2007) Evolution of Ground Support Practices at Agnico-Eagles’ LaRonde Division - Innovative Solutions to high-stress yielding ground. American and Canadian Rock Mechanics Associations $1^{\text {st }}$ Canada-U.S. Rock Mechanics Symposium. Vancouver, British Columbia.

Ortlepp, W.D. (2002) Dynamic Testing of Brunswick Mine Rockburst Support System. Steffen, Robertson and Kirsten (South Africa). Consulting report for Xstarta’s Brunswick Lead/Zinc Mine.

Plouffe, M. (2006) Dynamic versus static testing of tendons. CANMET report commissioned by the Canadian Deep Mining Research consortium.

Simser, B. (2003) Dynamic Testing of Strandlok Cables and 7/8” Rebar. Internal report Noranda Technology Centre commissioned by Falconbridge Limited.

Simser, B., Andrieux, P., Mercier-Langevin, F., Parrott, T. and Turcotte, P. (2006) Field behaviour and failure modes of modified conebolts at the Craig, LaRonde and Brunswick Mines in Canada. Deep and High Stress Mining. Quebec City, Canada. October 2-4, 2006, Section 36.

Turner, M. and Green, T. (2005) Threadbar bolts in a seismically active, high stress, high yield environment - OtterJuan Mine, Kambalda. RASIM6, Controlling Seismic Risk, Sixth International Symposium on Rockburst and Seismicity in Mines, 9-11 March 2005, Perth, Australia.

Villaescusa, E., (2007) Ground Support Research at the WA School of Mines. Canadian Institute of Mining, Annual General Meeting, Montreal, Canada, 2007. 